\title{
Donor Selection for Adults and Pediatrics
}

\author{
Francis Ayuk and Adriana Balduzzi
}

\subsection{Introduction}

It is known that multiple factors impact on transplantation outcome; the heaviest ones are diseaserelated (disease refractoriness, phase, clonal abnormalities, etc. in malignancies and disease type and associated rejection risk in non-malignant diseases) and patient-related (age, comorbidities, infectious diseases/colonization, etc.). Moreover, donor-related issues and stem cell source may influence the extent of disease control and transplant-related mortality.

The availability of a suitable stem cell graft is an absolute prerequisite for the performance of allo-HSCT. Beyond donor-recipient histocompatibility, other factors such as stem cell source, donor age and gender, donor-recipient CMV status, and $\mathrm{ABO}$ compatibility may play a role on transplant outcome.

In this chapter we discuss results of studies investigating these factors and conclude with an algorithm for donor selection. Issues which are peculiar to pediatric recipients are also analyzed and discussed.

\section{F. Ayuk}

Department of Stem Cell Transplantation, University Medical Center Hamburg-Eppendorf (UKE), Hamburg, Germany

\footnotetext{
A. Balduzzi $(\square)$

Outpatient Hematology and Transplant Department, Clinica Pediatrica, Università degli Studi di Milano Bicocca, Ospedale San Gerardo, Monza, Italy e-mail: abalduzzi@fondazionembbm.it
}

\subsection{Donor HLA Compatibility (See Chap. 9)}

The outcome of HSCT depends in part on the matching between the donor and the recipient for the human leukocyte antigens (HLA), encoded by a group of genes on chromosome 6; genes and products are labelled as major histocompatibility complex (MHC). The HLA system is the most polymorphic genetic region known in the human genome. A set of HLA gene alleles, called haplotype, is inherited from each parent; therefore, the probability that a child inherited and shares both parental haplotypes with a full sibling is $25 \%$. Such HLA-identical sibling is still considered an optimal donor.

The most relevant genes for transplantation belong to class I (HLA-A, HLA-B, and HLA-Cw) and class II (HLA-DR, HLA-DQ, and HLA-DP). HLA compatibility with the donor is usually defined by high-resolution typing (four digits) for ten alleles, HLA-A, HLA-B, HLA-C, HLA-DR, and HLA-DQ (Petersdorf 2013), even though there is an increasing evidence supporting the relevance of DPB1 matching (reviewed by Fleischhauer and Shaw 2017).

The concept of "compatibility" for CB donor-recipient pairs is still under debate. Any $\mathrm{CB}$ unit which was $6 / 6$ or $5 / 6$ matched was labelled HLA compatible (MD), in the past as defined by low-resolution typing at A and B loci and high-resolution typing at the DRB1 locus; more recently, high resolution for at least A, B, 
$\mathrm{C}$, and DRB1 loci is requested, and progressively the same criteria used for volunteer donors are considered to define CB HLA matching (Eapen et al. 2017).

\subsection{Donor Selection for Adult Patients}

\subsubsection{Donor Type (Summarized in Fig. 12.1)}

\subsubsection{Matched Related Siblings and Unrelated Donors}

Donor-recipient histocompatibility is one of the key variables in allo-HSCT. An HLAidentical sibling donor is generally considered the best donor for allo-HSCT; however less than a third of patients will have one available. Unrelated donor registries worldwide now include more than about 30 million volunteer donors, most of them in North America and Europe (www.bmdw.org). The probability of finding a fully MUD (8/8 or $10 / 10)$ varies on average between $16 \%$ and $75 \%$ (Gragert et al. 2014; Buck et al. 2016) depending on ethnicity, with lowest and highest probabilities in patients of African and European descent, respectively. Increasing ethnic diversity will with time further limit the chances of finding a fully matched unrelated donor.

Till date no randomized trial has compared outcome of transplants from different donors. However, one prospective (Yakoub-Agha et al. 2006) and several retrospective analyses indicate that outcomes after MSD and fully MUD (8/8 or 10/10) HSCT are comparable (Schetelig et al. 2008; Szydlo et al. 1997; Arora et al. 2009; Ringden 2009; Gupta et al. 2010; Woolfrey et al. 2010; Saber et al. 2012). Increase in donorrecipient HLA disparity in HLA-A, HLA-B, HLA-C, or HLA-DRB1 is associated with poorer outcome after unrelated donor transplantation (Lee et al. 2007; Shaw et al. 2010; Woolfrey et al. 2011; Horan et al. 2012; Fürst et al. 2013; Pidala et al. 2014; Verneris et al. 2015). The overall decrease in survival can be explained by the increase in NRM with no positive effect on relapse. Disparities in HLA-DQB1 as well as $\mathrm{C}$-allele disparities in $\mathrm{C}^{*} 03: 03$ vs 03:04 have been reported to be permissive with no negative effects on outcome (Lee et al. 2007; Fürst et al. 2013; Morishima et al. 2015; Pidala et al. 2014; Crivello et al. 2016). Disparities in HLA-DPB1 are observed in the majority of HLA-A, HLA-B, HLA-C, and HLA-DQB 1

\section{Algorithm for donor selection for adult patients with hematological malignancies}

\section{HLA-identical sibling donor}

HLA-10/10 matched unrelated donor

Beyond HLA: donor age> CMV-matching, sex-matching, ABO-matching 
(10/10) MUD transplants. Nonpermissive mismatches in DPB1 defined according to T-cell epitope matching (Zino et al. 2004; Crocchiolo et al. 2009; Fleischhauer et al. 2012; Pidala et al. 2014; Oran et al. 2018) or allele cell-surface expression levels (Petersdorf et al. 2015) are associated with poorer outcome compared to full matches or permissive mismatches. Associations of permissive DPB1 mismatches with lower relapse incidence are currently being explored (Fleischhauer and Beelen 2016; Fleischhauer and Shaw 2017).

\subsubsection{Haploidentical Related Donors}

Improvements in transplant technology including pre-transplant ATG (Huang et al. 2006), PT-CY (Luznik et al. 2008), and alpha-beta TCD (Bertaina et al. 2014) have led to improved outcome and rapidly increasing use of haploidentical related donor transplantation (Passweg et al. 2014). Several retrospective comparison studies have reported similar outcome for haploidentical and MUD transplants (summarized by Fuchs 2017). The results of prospective comparative trials are eagerly awaited.

\subsubsection{Role of Non-HLA Donor Characteristics}

Besides donor-recipient histocompatibility, donor age is now considered one of, if not the most relevant, the non-HLA donor characteristics in unrelated donor HSCT (Kollman et al. 2001, 2016; Wang et al. 2018) with a 2-year survival being $3 \%$ better when a donor 10 years younger is selected (Shaw et al. 2018). These findings have impacted daily practice such that the percentage of selected donors under 30 years of age has increased from 36\% in the period 1988-2006 to $51 \%$ in $1999-2011$ up to $69 \%$ in $2012-2014$ (Kollman et al. 2016).

Matching for patient/recipient CMV serostatus also seems to be a determinant of transplant outcome with best outcome seen in seronegative patients receiving seronegative grafts (Ljungman 2014; Kalra et al. 2016; Shaw et al. 2017).
The impact of sex mismatch on outcome is more controversial, possibly reflecting different definitions of sex mismatch, which has been considered only for male recipients (Gratwohl et al. 2009, 2017; Nakasone et al. 2015) or for both male and female in others (Kollman et al. 2016). Interestingly, all three studies confining sex mismatch to male recipients reported a significant impact for this variable, albeit possibly dependent on conditioning regimen.

The impact of ABO (blood group) compatibility on outcome has been reported to be modest and seems to have further diminished in recent years probably due to changes in transplant practice including less frequent use of bone marrow grafts (Seebach et al. 2005; Kollman et al. 2016; Shaw et al. 2018).

The impact of non-HLA donor characteristics may be less conspicuous in matched and mismatched related donor transplantations using PT-CY. It must however be taken into consideration that the close association of donor age and donor-patient relation on the one hand with patient age on the other hand makes these analyses more complex (McCurdy et al. 2018; Robinson et al. 2018). Larger patient cohorts and prospective studies are required for more definite conclusions.

\subsubsection{Donor Choice According to Stem Cell Source}

The three graft sources for allo-HSCT are BM, PBSC, and CB. In matched related donor and unrelated donor HSCT, survival outcome has been similar for BM and PBSC. However hematological recovery is more rapid and graft rejection less frequent after $\mathrm{PB}$ compared to $\mathrm{BM}$ HSCT, while the incidence of chronic GvHD and, to a lesser extent, acute GvHD tends to be higher after PB HSCT (Bensinger et al. 2001; Couban et al. 2002; Schmitz et al. 2002; Couban et al. 2016; Anasetti et al. 2012). In allo-HSCT for nonmalignant diseases, in particular for SAA, $\mathrm{BM}$ is still the preferred stem cell source in highincome countries, despite improvements in outcome after PB HSCT (Schrezenmeier et al. 2007; 
Chu et al. 2011; Bacigalupo et al. 2012; Kumar et al. 2016).

Traditionally BM has been used as stem cell source for haploidentical HSCT with PT-CY (Luznik et al. 2008), while GCSF-stimulated BM has been used for haploidentical HSCT with ATG (Huang et al. 2006) and PBSC for haploidentical HSCT with alpha-beta T-cell depletion (Bertaina et al. 2014). There are no prospective studies comparing different stem cell sources within these strategies. When PT-CY is used, PBSC seems to be associated with a higher risk of acute and chronic GvHD and lower risk of relapse in patients with leukemia (Bashey et al. 2017).

The use of umbilical CB grafts continues to decrease with the rise in numbers of haploidentical transplants performed (Passweg et al. 2014). Due to the limited number of stem cells per unit, $\mathrm{CB}$ grafts have been more frequently used in pediatric HSCT and will be discussed in that section and in the specific CB Chapter.

\subsubsection{Anti-HLA Antibodies}

The abovementioned improvements in transplant technology have led to an increased use of grafts from HLA-mismatched donors. Detection of donor-specific anti-HLA antibodies in the patients' serum has been associated with increased risk of graft failure and also poorer survival of those patients with graft failure (Ciurea et al. 2015) after haploidentical HSCT. The risk of graft failure and overall mortality may however also depend on the type and intensity of TCD used. The EBMT recently published a consensus guideline on detection and treatment of donor-specific antibodies in haploidentical HSCT (Ciurea et al. 2018).

\subsection{Donor Selection for Pediatric Patients}

Donor selection criteria may vary between adult and pediatric recipients. According to the "motto" of the Pediatric Disease Working Party, "children are not small adults," besides the size, what makes HSCT in children different is mainly related with indications and the biology of a growing individual.

\subsubsection{Pediatric Recipient Size}

In terms of size, the recipient weight may vary between few $\mathrm{Kg}$ in most patients transplanted for immunodeficiencies and a full adult size in some adolescents. The recommended cell dose in the graft is shown in Table 12.1 (Gluckmann 2012). The lower the recipient weight, the smaller is the amount of the requested absolute count in the graft, which makes the harvest easier, often matching the transplant center requests. An appropriate cell dose in the graft yields a lower risk of rejection, which is actually lowest in pediatrics. On the other hand, the lower amount of cells requested to ensure engraftment in children makes $\mathrm{CB}$ a more valuable source than in adults.

\subsubsection{Indications}

In terms of indications, according to the EBMT, nowadays $46 \%$ of the patients younger than 18 years who undergo HSCT are affected with nonmalignant diseases (Passweg et al. 2014), which are mainly inherited disorders, namely, immunodeficiencies, hemoglobinopaties, inborn errors of

Table 12.1 Number of cells according to stem cell source

\begin{tabular}{|l|l|l|l|l} 
& Volume collected & Med CD34 content & Med CD3 content & Target cell dose \\
\hline Bone marrow & $10-20 \mathrm{~mL} / \mathrm{kg}$ & $2-3 \times 10^{6} / \mathrm{kg}^{\mathrm{a}}$ & $25 \times 10^{6} / \mathrm{kg}$ & $>2 \times 10^{8} \mathrm{TNC} / \mathrm{kg}$ \\
\hline Peripheral blood & $150-400 \mathrm{~mL}$ & $8 \times 10^{6} / \mathrm{kg}$ & $250 \times 10^{6} / \mathrm{kg}$ & $5-10 \times 10^{6} \mathrm{CD} 34+/ \mathrm{kg}$ \\
\hline Umbilical cord blood & $80-160 \mathrm{~mL}$ & $0.2 \times 10^{6} / \mathrm{kg}$ & $2.5 \times 10^{6} / \mathrm{kg}$ & $>3 \times 10^{7} \mathrm{TNC} / \mathrm{kg}$
\end{tabular}

${ }^{\text {aPer }} \mathrm{kg}$ recipient body weight 
metabolism, and congenital bone marrow failures. As nonmalignant diseases do not benefit of any alloreactivity, the closest HLA matching (possibly "10 out of 10" HLA alleles) is recommended. On the contrary, a small degree of HLA incompatibility is tolerated in malignancies, as the detrimental effect of HLA disparity, triggering higher risk of GvHD and consequent higher risks of toxicity and mortality, might be counterbalanced by the socalled "graft-versus-leukemia" or "graft-versustumor" effect, which is the alloreactivity of immunocompetent donor cells potentially eradicating residual malignant cells in the patient and playing a role in the prevention of malignant disease recurrence.

\subsubsection{Donor Type}

Due to the decreasing size of modern families in the so-called Western countries, HLA-identical siblings are available in less than $25 \%$ of the children in need of a transplant, as shown by the few studies performing a "randomization by genetic chance," based on the availability of an HLAidentical sibling or not (Balduzzi et al. 2005). As a consequence, $75 \%$ of the patients may need to run a search for an unrelated donor.

Eligibility criteria for HSCT in malignant diseases varied overtime, resulting from the balance between the outcome of frontline and relapse chemotherapy protocols and the outcome of transplantation, which partially depends on the degree of compatibility within each donorrecipient pair. Similarly, the eligibility for transplantation in nonmalignant diseases increased as the safety profile of the procedure improved. Some patients are considered eligible for transplantation only in case an HLA-identical sibling is available; as the risk profile of the patient worsens, a broader degree of HLA mismatching is considered acceptable.

Within the International BFM Study Group, regardless of their relationship with their recipient, donors are defined as HLA-matched (MD) if the donor-recipient pairs are fully matched
$(10 / 10)$ or have a single allelic or antigenic disparity (9/10) or are defined mismatched donor (MMD) if the donor-recipient pairs have two (8/10) or more allelic or antigenic disparities, up to a different haplotype (Peters et al. 2015). Any donor who is not an HLA-identical sibling or a $\mathrm{MD}$, as defined above, is considered a MMD. Both MD and MMD could be either related or unrelated to their recipient. A related donor who is not an HLA-identical sibling is actually regarded as a MD, and GvHD prophylaxis is planned accordingly (Peters et al. 2015).

Recently, results from a BFM study showed that transplantation from a " 10 or 9 out of 10 " matched donor, either related or unrelated, was not inferior to transplantation from an HLAidentical sibling in terms of EFS, OS, and CIR in pediatric patients with ALL (Peters et al. 2015). As a consequence eligibility criteria for HSCT might be reviewed and extended to those for MSD HSCT, at least in ALL, and, possibly, considered for other malignant diseases. Therefore, an unrelated donor search activation and transplantation might be recommended in the future virtually for every child for whom an allo-HSCT is indicated. Disparities within donor-recipient pairs are progressively accepted as the risk profile of the patient increases.

Unfortunately some inherited disorders, in particular sickle cell disease (Gluckman et al. 2017) or other recessively inherited disease, which incidence is highly increased by a parental blood relation, have higher incidences in nonCaucasian ethnicities, which are less represented within stem cell donor banks. The consequence is that well-matched donors often lack when a perfect matching is crucial; progresses in haploidentical HSCT broadened its indications and may overcome this issue.

Depending on each transplant center experience, MMD might be preferred, carrying the advantage of prompt donor availability and flexible schedule and bringing higher degree of alloreactivity, potentially associated with lower relapse risk. HSCT from MMD is widely recommended when timing adjustment is crucial, as in 
advanced disease phase in malignancies and in case of post transplant relapse.

\subsubsection{Haploidentical Donors in Pediatrics}

Successful haploidentical HSCT mainly evolved in pediatrics over the last two decades from ex vivo T-cell depletion by CD34+-positive selection, to CD34+-negative selection, up to selective CD3 $\alpha \beta$ depletion, to allow other cells in the graft, potentially protecting from viral infections (Handgretinger et al. 2001; Klingebiel et al. 2010). In pediatrics, an improved immune recovery after TCR $\alpha \beta$-depleted haploidentical HSCT (Lang et al. 2015), a similar outcome between TCR $\alpha \beta$-depleted and matched sibling and matched unrelated donors HSCT in children with acute leukemia (Locatelli et al. 2017) and in nonmalignant diseases (Bertaina et al. 2014), was recently reported and confirmed by a multicenter phase I/II study (Lang et al. 2017). Moreover, some reports of PT-CY in pediatric show promising results (Jaiswal et al. 2016; Sawada et al. 2014; Wiebking et al. 2017).

One of the parents mostly serves as a donor in haploidentical donors for pediatric recipients. The choice between the mother and the father is still debated. Better survival was shown in patients transplanted from the mother than from the father (51\% vs $11 \% ; P<0.001)$, due to both reduced incidence of relapse and TRM, with a protective effect on the risk of failure (HR 0.42; $P=0.003$ ), possibly explained by transplacental leukocyte trafficking during pregnancy, inducing long-term, stable, reciprocal microchimerism in mother and child (Stern et al. 2008).

As donor-derived alloreactive NK cells have been shown to play a key role in the eradication of leukemic cells, favorable NK matching should guide donor selection (Stringaris and Barrett 2017; Mavers and Bertaina 2018). Moreover, anti-HLA antibodies should be checked and accounted for to guide donor selection.

\subsubsection{Stem Cell Source}

BM is usually recommended as stem cell source. A donor with a body weight allowing for a graft containing at least $3 \times 10^{8}$ nucleated cells $/ \mathrm{kg}$ recipient body weight and $3 \times 10^{6} \mathrm{CD} 34+$ cells/ $\mathrm{kg}$ body weight should be selected, in order to yield more than $95 \%$ neutrophil engraftment chances at a median of 21 days in the setting of hematological malignant diseases (Simonin et al. 2017).

It is rare in pediatrics to require PB just in order to obtain an adequate amount of cells to ensure engraftment, as the absolute cell dose needed rarely overcomes the maximum amount which could be harvested from a donor. As higher numbers of CD3 cells are obtained in PB grafts, it is recommended not to exceed an amount of $10 \times 10^{8} \mathrm{CD} 3+$ cells $/ \mathrm{kg}$ recipient body weight.

The increased risk of chronic GvHD, and possibly acute, after PBSC transplantation, as compared to BM, is commonly reported. In a recent European retrospective study, including 2584 pediatric patients transplanted from 2003 to 2012 for ALL, both TRM and chronic GvHD appeared significantly higher after PBSC, as compared with other SC sources, despite the overall survival was similar for both stem cell sources (Simonin et al. 2017). In the prospective ALLSCT-BFM 2003 study, the same OS was reported, and no difference could be demonstrated in TRM, acute GvHD, and relapse, whichever the stem cell source in the two cohorts of patients transplanted from HLA-identical siblings and other matched donors. Nevertheless, within patients transplanted from HLA-identical siblings, the cumulative incidence of chronic GvHD was higher in $\mathrm{PB}$ compared with $\mathrm{BM}$ recipients (Peters et al. 2015).

Reinforced GvHD prophylaxis may be recommended when PBSC are used, mainly when no serotherapy is included as for GvHD prophylaxis, as in most protocols in the HLA-identical sibling setting in malignancies (Simonin et al. 2017). 
Nowadays, in the ongoing prospective ALL-IBFM HSCT trial (FORUM), the algorithm for choosing stem cell source recommends $\mathrm{BM}$ as the first choice. To date, there is no demonstration for a better GVL effect after PB HSCT in the pediatric population.

Due to the increased risk of cGvHD after PB transplant, which is almost consistent among investigators, it is definitely recommended to avoid PB in nonmalignant disorders.

From the first $\mathrm{CB}$ transplantation performed for a Fanconi anemia patient in 1987, CB appeared as a useful and an efficient stem cell source, due to two major features: high proliferative capacity, allowing engraftment despite 1-log fewer cells, and immune plasticity, allowing a wider HLA disparity within each donor recipient pair (Gluckman et al. 1989).

The possibility to adopt less stringent HLAmatching criteria enlarged the availability of grafts to at least $90 \%$ of the pediatric patients in need of an allogeneic transplant (Eapen et al. 2017). According to Eurocord consortium recommendations, unrelated $\mathrm{CB}$ with two or less HLA disparities typed in low resolution (i.e., two digit) for class I (A and B loci) and high resolution (i.e., four-digit) for class II (DRB1 locus) and with more than $2.5 \times 10^{7}$ nucleated cell dose/ $\mathrm{kg}$ or $2 \times 10^{5} \mathrm{CD} 34+$ cells $/ \mathrm{kg}$ are suitable for engraftment (Gratwohl et al. 2009). Recent studies from both Eurocord, NetCord, EBMT, and CIBMTR recommend high-resolution HLA typing for $\mathrm{A}, \mathrm{B}, \mathrm{C}$, and DRB1 and a maximum of 1 or 2 mismatched loci with a cellularity of $3 \times 10^{7}$ $\mathrm{TNC} / \mathrm{kg}$ or higher (Eapen et al. 2014).

Two prospective studies could demonstrate no benefit of double CB in pediatric patients transplanted for malignant diseases (Wagner et al. 2014; Michel et al. 2016).

\subsubsection{Other Donor-Recipient- Related Factors}

Besides HLA compatibility and stem cell source, also donor age, gender, female parity, weight,
ABO blood group, and viral serological status should be considered in the decision-making process for donor selection, whenever more than one donor were available, which may not be often the case (Wang et al. 2018).

Most studies report that a young donor is better than an older one. Few studies also report that a male donor is better for a male recipient and better than a multiparous woman for any recipient, even though this finding is not consistent through the literature. The donor gender effect may be mild and need larger series of patients to be demonstrated (Friedrich et al. 2018). Unfavorable weight disparity, with donors weighing less than their recipient, should be avoided, when possible (Styczynski et al. 2012). CMV-IgG, as well as EBV-positive patients, should be grafted from CMV- and EBV-positive donors, respectively (Jeljeli et al. 2014; Bontant et al. 2014). ABO matching is usually preferred, especially instead of a major or even minor incompatibility (Booth et al. 2013). Donor location might also be considered, as oversea deliveries increase the time elapsing between collection and infusion, thus reduce cell viability and potentially jeopardize engraftment. More recently, KIR genotyping would allow to identify alloreactive donors who may contribute to prevent relapse also in the non-haploidentical setting (Mavers and Bertaina 2018).

Even though it is mainly clear which variant should be preferred within each variable, there is no consensus regarding the hierarchical order by which the factors above should be combined. In a recent survey within the Pediatric Diseases Working Party of the EBMT, the features above were listed in the following order of importance, on the average, but evaluations widely differed among responders:

1. HLA compatibility, with $10 / 10$ better than 9/10 or worse matching

2. CMV serological status of positive donors in case of positive recipients

3. BM as stem cell source

4. Donor age, being preferable a younger donor compared with an older one 
5. Donor gender, with a male donor preferred, particularly for a male recipient

6. ABO major compatibility

7. Donor center location

8. ABO minor compatibility (unpublished data)

Moreover, the presence of anti-HLA antibodies directed to any mismatched HLA alleles should be ruled out, mainly in heavily transfused nonmalignant diseases, such as hemoglobinopaties or bone marrow failures (Ciurea et al. 2018).

\section{Key Points}

- An HLA-identical sibling is considered a donor of first choice.

- For patients with hematological malignancies, transplantation from fully HLA-MUD (8/8 or 10/10) is not inferior to transplantation from HLA-identical siblings in terms of EFS.

- The choice of alternative donors (haploidentical related donors, cord blood, mismatched unrelated donors) depends on center experience, urgency of transplant procedure, and detection of donorspecific anti-HLA antibodies.

- For pediatric patients and patients with nonmalignant disorders, BM is the preferred stem cell source.

- For adult patients with hematological malignancies, survival outcome after HSCT with PBSC and BM is comparable.

- In URD transplantation, donor age is probably the most relevant non-HLA donor factor.

\section{References}

Anasetti C, Logan BR, Lee SJ, et al. Peripheral-blood stem cells versus bone marrow from unrelated donors. N Engl J Med. 2012;367:1487-96.

Arora M, Weisdorf DJ, Spellman SR, et al. HLA-identical sibling compared with $8 / 8$ matched and mismatched unrelated donor bone marrow transplant for chronic phase chronic myeloid leukemia. J Clin Oncol. 2009;27:1644-52.
Bacigalupo A, Socie G, Schrezenmeier H, et al. Bone marrow versus peripheral blood as the stem cell source for sibling transplants in acquired aplastic anemia: survival advantage for bone marrow in all age groups. Haematologica. 2012;97:1142-8.

Balduzzi A, Valsecchi MG, Uderzo C, et al. Chemotherapy versus allogeneic transplantation for very-high-risk childhood acute lymphoblastic leukaemia in first complete remission: comparison by genetic randomisation in an international prospective study. Lancet. 2005;366:635-42.

Bashey A, Zhang MJ, McCurdy SR, et al. Mobilized peripheral blood stem cells versus unstimulated bone marrow as a graft source for T-cell-replete haploidentical donor transplantation using post-transplant cyclophosphamide. J Clin Oncol. 2017;35:3002-9.

Bensinger WI, Martin PJ, Storer B, et al. Transplantation of bone marrow as compared with peripheralblood cells from HLA-identical relatives in patients with hematologic cancers. N Engl J Med. 2001;344:175-81.

Bertaina A, Merli P, Rutella S, et al. HLA-haploidentical stem cell transplantation after removal of $\alpha \beta+\mathrm{T}$ and $\mathrm{B}$ cells in children with nonmalignant disorders. Blood. 2014;124:822-6.

Bontant T, Sedlaçek P, Balduzzi A, et al. Survey of CMV management in pediatric allogeneic HSCT programs, on behalf of the inborn errors, infectious diseases and pediatric diseases working parties of EBMT. Bone Marrow Transplant. 2014;49:276-9.

Booth GS, Gehrie EA, Bolan CD, Savani BN. Clinical guide to ABO-incompatible allogeneic stem cell transplantation. Biol Blood Marrow Transplant. 2013;19:1152-8.

Buck K, Wadsworth K, Setterholm M, et al. HighResolution Match Rate of 7/8 and 9/10 or Better for the Be The Match Unrelated Donor Registry. Biol Blood Marrow Transplant. 2016;22:759-63.

Chu R, Brazauskas R, Kan F, et al. Comparison of outcomes after transplantation of G-CSF-stimulated bone marrow grafts versus bone marrow or peripheral blood grafts from HLA-matched sibling donors for patients with severe aplastic anemia. Biol Blood Marrow Transplant. 2011;17:1018-24.

Ciurea SO, Thall PF, Milton DR, et al. Complementbinding donor-specific anti-HLA antibodies and risk of primary graft failure in hematopoietic stem cell transplantation. Biol Blood Marrow Transplant. 2015;21:1392-8.

Ciurea SO, Cao K, Fernadez-Vina M, et al. The European Society for Blood and Marrow Transplantation (EBMT) consensus guidelines for the detection and treatment of donor-specific anti-HLA antibodies (DSA) in haploidentical hematopoietic cell transplantation. Bone Marrow Transplant. 2018;53:521-34.

Couban S, Simpson DR, Barnett MJ, et al. A randomized multicenter comparison of bone marrow and peripheral blood in recipients of matched sibling allogeneic transplants for myeloid malignancies. Blood. 2002; 100:1525-31. 
Couban S, Aljurf M, Lachance S, et al. Filgrastimstimulated bone marrow compared with filgrastimmobilized peripheral blood in myeloablative sibling allografting for patients with hematologic malignancies: a randomized Canadian Blood and Marrow Transplant Group Study. Biol Blood Marrow Transplant. 2016;22:1410-5.

Crivello P, Heinold A, Rebmann V, et al. Functional distance between recipient and donor HLA-DPB1 determines nonpermissive mismatches in unrelated HCT. Blood. 2016;128:120-9.

Crocchiolo R, Zino E, Vago L, et al. Gruppo Italiano Trapianto di Midollo Osseo, Cellule Staminale Ematopoietiche (CSE) e Terapia Cellulare; Italian Bone Marrow Donor Registry. Nonpermissive HLADPB1 disparity is a significant independent risk factor for mortality after unrelated hematopoietic stem cell transplantation. Blood. 2009;114:1437-44.

Eapen M, Klein JP, Ruggeri A, et al. Impact of allelelevel HLA matching on outcomes after myeloablative single unit umbilical cord blood transplantation for hematologic malignancy. Blood. 2014;123:133-4.

Eapen M, Wang T, Veys PA, et al. Allele-level HLA matching for umbilical cord blood transplantation for non-malignant diseases in children: a retrospective analysis. Lancet Haematol. 2017;4:e325-33.

Fleischhauer K, Beelen DW. HLA mismatching as a strategy to reduce relapse after alternative donor transplantation. Semin Hematol. 2016;53:57-64.

Fleischhauer K, Shaw BE. HLA-DP in unrelated hematopoietic cell transplantation revisited: challenges and opportunities. Blood. 2017;130:1089-96.

Fleischhauer K, Shaw BE, Gooley T, et al. Effect of T-cell-epitope matching at HLA-DPB1 in recipients of unrelated-donor haemopoietic-cell transplantation: a retrospective study International Histocompatibility Working Group in hematopoietic cell transplantation. Lancet Oncol. 2012;13:366-74.

Friedrich P, Guerra-García P, Stetson A, et al. Young female donors do not increase the risk of graftversus-host disease or impact overall outcomes in pediatric HLA-matched sibling hematopoietic stem cell transplantation. Biol Blood Marrow Transplant. 2018;24:96-102.

Fuchs EJ. Related haploidentical donors are a better choice than matched unrelated donors: point. Blood Adv. 2017;1:397-400.

Fürst D, Müller C, Vucinic V, et al. High-resolution HLA matching in hematopoietic stem cell transplantation: a retrospective collaborative analysis. Blood. 2013;122:3220-9.

Gluckman E, Broxmeyer HA, Auerbach AD, et al. Hematopoietic reconstitution in a patient with Fanconi's anemia by means of umbilical-cord blood from an HLA-identical sibling. $\mathrm{N}$ Engl $\mathrm{J}$ Med. 1989;321:1174-8.

Gluckman E, Cappelli B, Bernaudin F, et al. Sickle cell disease: an international survey of results of HLAidentical sibling hematopoietic stem cell transplantation. Blood. 2017;129:1548-56.
Gluckmann E (2012) Choice of the donor according to HLA typing and stem cell source. EBMT handbook.

Gragert L, Eapen M, Williams E, et al. HLA Match likelihoods, for hematopoietic stem-cell grafts in the U.S. registry. N Engl J Med. 2014;371:339-48.

Gratwohl A, Stern M, Brand R, et al. European Group for Blood and Marrow Transplantation and the European Leukemia Net. Risk score for outcome after allogeneic hematopoietic stem cell transplantation: a retrospective analysis. Cancer. 2009;115:4715-26.

Gratwohl A, Sureda A, Cornelissen J, et al. Alloreactivity: the Janus-face of hematopoietic stem cell transplantation. Leukemia. 2017;31:1752-9.

Gupta V, Tallman MS, He W, et al. Comparable survival after HLA-well-matched unrelated or matched sibling donor transplantation for acute myeloid leukemia in first remission with unfavorable cytogenetics at diagnosis. Blood. 2010;116:1839-48.

Handgretinger R, Klingebiel T, Lang P, et al. Megadose transplantation of purified peripheral blood CD34(+) progenitor cells from HLA-mismatched parental donors in children. Bone Marrow Transplant. 2001;27:777-83.

Horan J, Wang T, Haagenson M, et al. Evaluation of HLA matching in unrelated hematopoietic stem cell transplantation for nonmalignant disorders. Blood. 2012; 120:2918-24.

Huang XJ, Liu DH, Liu KY, et al. Haploidentical hematopoietic stem cell transplantation without in vitro T-cell depletion for the treatment of hematological malignancies. Bone Marrow Transplant. 2006;38:291-7.

Jaiswal SR, Chakrabarti A, Chatterjee S, et al. Haploidentical peripheral blood stem cell transplantation with post-transplantation cyclophosphamide in children with advanced acute leukemia with fludarabine-, busulfan-, and melphalan-based conditioning. Biol Blood Marrow Transplant. 2016;22:499-504.

Jeljeli M, Guérin-El Khourouj V, Porcher R, et al. Relationship between cytomegalovirus (CMV) reactivation, CMV-driven immunity, overall immune recovery and graft-versus-leukaemia effect in children. Br J Haematol. 2014;166:229-39.

Kalra A, Williamson T, Daly A, et al. Impact of donor and recipient cytomegalovirus serostatus on outcomes of antithymocyte globulin-conditioned hematopoietic cell transplantation. Biol Blood Marrow Transplant. 2016;22:1654-63.

Klingebiel T, Cornish J, Labopin M, et al. Results and factors influencing outcome after fully haploidentical hematopoietic stem cell transplantation in children with very high-risk acute lymphoblastic leukemia: impact of center size: an analysis on behalf of the Acute Leukemia and Pediatric Disease Working Parties of the European Blood and Marrow Transplant group. Blood. 2010;115:3437-46.

Kollman C, Howe CW, Anasetti C, et al. Donor characteristics as risk factors in recipients after transplantation of bone marrow from unrelated donors: the effect of donor age. Blood. 2001;98:2043-51. 
Kollman C, Spellman SR, Zhang MJ, et al. The effect of donor characteristics on survival after unrelated donor transplantation for hematologic malignancy. Blood. 2016;127:260-7.

Kumar R, Kimura F, Ahn KW, et al. Comparing outcomes with bone marrow or peripheral blood stem cells as graft source for matched sibling transplants in severe aplastic anemia across different economic regions. Biol Blood Marrow Transplant. 2016;22:932-40.

Lang P, Feuchtinger T, Teltschik HM, et al. Improved immune recovery after transplantation of $\mathrm{TCR} \alpha \beta /$ CD19-depleted allografts from haploidentical donors in pediatric patients. Bone Marrow Transplant. 2015;50(Suppl 2):S6-10.

Lang PL, Schlegel PG, Meisel R, et al. Safety and efficacy of Tcr alpha/beta and CD19 depleted haploidentical stem cell transplantation following reduced intensity conditioning in children: results of a prospective multicenter phase I/II clinical trial. Blood. 2017;130:214.

Lee SJ, Klein J, Haagenson M, et al. High-resolution donor-recipient HLA matching contributes to the success of unrelated donor marrow transplantation. Blood. 2007;110:4576-83.

Ljungman P. The role of cytomegalovirus serostatus on outcome of hematopoietic stem cell transplantation. Curr Opin Hematol. 2014;21:466-9.

Locatelli F, Merli P, Pagliara D, et al. Outcome of children with acute leukemia given HLA-haploidentical HSCT after $\alpha \beta$ T-cell and B-cell depletion. Blood. 2017;130:677-85.

Luznik L, O'Donnell PV, Symons HJ, et al. HLAhaploidentical bone marrow transplantation for hematologic malignancies using nonmyeloablative conditioning and high-dose, posttransplantation cyclophosphamide. Biol Blood Marrow Transplant. 2008;14:641-50.

Mavers M, Bertaina A. High-risk leukemia: past, present, and future role of NK cells. J Immunol Res. 2018 Apr;15:2018.

McCurdy SR, Zhang MJ, St Martin A, et al. Effect of donor characteristics on haploidentical transplantation with posttransplantation cyclophosphamide. Blood Adv. 2018;2:299-307.

Michel G, Galambrun C, Sirvent A, et al. Single- vs double-unit cord blood transplantation for children and young adults with acute leukemia or myelodysplastic syndrome. Blood. 2016;127:3450-7.

Morishima Y, Kashiwase K, Matsuo K, et al. Biological significance of HLA locus matching in unrelated donor bone marrow transplantation. Japan Marrow Donor Program. Blood. 2015;125:1189-97.

Nakasone H, Remberger M, Tian L, et al. Risks and benefits of sex-mismatched hematopoietic cell transplantation differ according to conditioning strategy. Haematologica. 2015;100:1477-85.

Oran B, Saliba RM, Carmazzi Y, et al. Effect of nonpermissive HLA-DPB1 mismatches after unrelated allogeneic transplantation with in vivo T-cell depletion. Blood. 2018;131:1248-57.
Passweg JR, Baldomero H, Peters C, et al. European Society for Blood and Marrow Transplantation EBMT. Hematopoietic SCT in Europe: data and trends in 2012 with special consideration of pediatric transplantation. Bone Marrow Transplant. 2014;49:744-50.

Peters C, Schrappe M, von Stackelberg A, et al. Stem-cell transplantation in children with acute lymphoblastic leukemia: a prospective international multicenter trial comparing sibling donors with matched unrelated donors-The ALL-SCT-BFM-2003 trial. J Clin Oncol. 2015;33:1265-74.

Petersdorf EW. The major histocompatibility complex: a model for understanding graft-versus-host disease. Blood. 2013;122:1863-72.

Petersdorf EW, Malkki M, O'hUigin C, et al. High HLA-DP expression and graft-versus host disease. N Engl J Med. 2015;373:599-609.

Pidala J, Lee SJ, Ahn KW, et al. Nonpermissive HLADPB1 mismatch increases mortality after myeloablative unrelated allogeneic hematopoietic cell transplantation. Blood. 2014;124:2596-606.

Robinson TM, Fuchs EJ, Zhang MJ, et al. Related donor transplants: has posttransplantation cyclophosphamide nullified the detrimental effect of HLA mismatch? Blood Adv. 2018;2:1180-6.

Saber W, Opie S, Rizzo JD, et al. Outcomes after matched unrelated donor versus identical sibling hematopoietic cell transplantation in adults with acute myelogenous leukemia. Blood. 2012;119:3908-16.

Sawada A, Shimizu M, Isaka K, et al. Feasibility of HLAhaploidentical hematopoietic stem cell transplantation with post-transplantation cyclophosphamide for advanced pediatric malignancies. Pediatr Hematol Oncol. 2014;31:754-64.

Schetelig J, Bornhauser M, Schmid C, et al. Matched unrelated or matched sibling donors result in comparable survival after allogeneic stem-cell transplantation in elderly patients with acute myeloid leukemia: a report from the cooperative German Transplant Study Group. J Clin Oncol. 2008;26:5183-91.

Schmitz N, Beksac M, Hasenclever D, et al. Transplantation of mobilized peripheral blood cells to HLA-identical siblings with standard-risk leukemia. Blood. 2002;100:761-7.

Schrezenmeier H, Passweg JR, Marsh JC, et al. Worse outcome and more chronic GVHD with peripheral blood progenitor cells than bone marrow in HLA-matched sibling donor transplants for young patients with severe acquired aplastic anemia. Blood. 2007;110:1397-400.

Seebach JD, Stussi G, Passweg JR, et al. ABO blood group barrier in allogeneic bone marrow transplantation revisited. Biol Blood Marrow Transplant. 2005;11:1006-13.

Shaw BE, Arguello R, Garcia-Sepulveda CA, Madrigal JA. The impact of HLA genotyping on survival following unrelated donor haematopoietic stem cell transplantation. Br J Haematol. 2010;150:251-8.

Shaw BE, Mayor NP, Szydlo RM, et al. Recipient/donor HLA and CMV matching in recipients of T-cell- 
depleted unrelated donor haematopoietic cell transplants. Bone Marrow Transplant. 2017;52:717-25.

Shaw BE, Logan BR, Spellman SR, et al. Development of an unrelated donor selection score predictive of survival after HCT: donor age matters most. Biol Blood Marrow Transplant. 2018;24:1049-56.

Simonin M, Dalissier A, Labopin M, et al. More chronic GvHD and non-relapse mortality after peripheral blood stem cell compared with bone marrow in hematopoietic transplantation for paediatric acute lymphoblastic leukemia: a retrospective study on behalf of the EBMT Paediatric Diseases Working Party. Bone Marrow Transplant. 2017;52:1071-3.

Stern M, Ruggeri L, Mancusi A, et al. Survival after T cell-depleted haploidentical stem cell transplantation is improved using the mother as donor. Blood. 2008;112:2990-5.

Stringaris K, Barrett AJ. The importance of natural killer cell killer immunoglobulin-like receptormismatch in transplant outcomes. Curr Opin Hematol. 2017;24:489-95.

Styczynski J, Balduzzi A, Gil L, et al. Risk of complications during hematopoietic stem cell collection in pediatric sibling donors: a prospective European Group for Blood and Marrow Transplantation Pediatric Diseases Working Party study. Blood. 2012;119:2935-42.

Szydlo R, Goldman JM, Klein JP, et al. Results of allogeneic bone marrow transplants for leukemia using donors other than HLA-identical siblings. J Clin Oncol. 1997; 15:1767-77.

Verneris MR, Lee SJ, Ahn KW, et al. HLA mismatch is associated with worse outcomes after unrelated donor reduced-intensity conditioning hematopoietic cell transplantation: an analysis from the Center for
International Blood and Marrow Transplant Research. Biol Blood Marrow Transplant. 2015;21:1783-9.

Wagner JE, Eapen M, Carter S, et al. One-unit versus twounit cord-blood transplantation for hematologic cancers. N Engl J Med. 2014;371:1685-94.

Wang Y, Wu DP, Liu QF, et al. Donor and recipient age, gender and $\mathrm{ABO}$ incompatibility regardless of donor source: validated criteria for donor selection for haematopoietic transplants. Leukemia. 2018;32:492-8.

Wiebking V, Hütker S, Schmid I, et al. Reduced toxicity, myeloablative HLA-haploidentical hematopoietic stem cell transplantation with post-transplantation cyclophosphamide for sickle cell disease. Ann Hematol. 2017;96:1373-7.

Woolfrey A, Lee SJ, Gooley TA, et al. HLA-allele matched unrelated donors compared to HLA-matched sibling donors: role of cell source and disease risk category. Biol Blood Marrow Transplant. 2010;16:1382-7.

Woolfrey A, Klein JP, Haagenson M, et al. HLA-C antigen mismatch is associated with worse outcome in unrelated donor peripheral blood stem cell transplantation. Biol Blood Marrow Transplant. 2011;17:885-92.

Yakoub-Agha I, Mesnil F, Kuentz M, et al. Allogeneic marrow stem-cell transplantation from human leukocyte antigen-identical siblings versus human leukocyte antigen-allelic-matched unrelated donors (10/10) in patients with standard-risk hematologic malignancy: a prospective study from the French Society of Bone Marrow Transplantation and Cell Therapy. J Clin Oncol. 2006;24:5695-702.

Zino E, Frumento G, Marktel S, et al. A T-cell epitope encoded by a subset of HLA-DPB1 alleles determines nonpermissive mismatches for hematologic stem cell transplantation. Blood. 2004;103:1417-24.

Open Access This chapter is licensed under the terms of the Creative Commons Attribution 4.0 International License (http://creativecommons.org/licenses/by/4.0/), which permits use, sharing, adaptation, distribution and reproduction in any medium or format, as long as you give appropriate credit to the original author(s) and the source, provide a link to the Creative Commons license and indicate if changes were made.

The images or other third party material in this chapter are included in the chapter's Creative Commons license, unless indicated otherwise in a credit line to the material. If material is not included in the chapter's Creative Commons license and your intended use is not permitted by statutory regulation or exceeds the permitted use, you will need to obtain permission directly from the copyright holder.

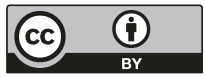

